\title{
Cytotoxicity of five fluoroquinolone and two nonsteroidal anti-inflammatory benzalkonium chloride-free ophthalmic solutions in four corneoconjunctival cell lines
}

\author{
This article was published in the following Dove Press journal: \\ Clinical Ophthalmology \\ 16 September 2010 \\ Number of times this article has been viewed
}

\section{Masahiko Ayaki ${ }^{1}$ \\ Atsuo Iwasawa ${ }^{2}$ \\ Mitsutaka Soda ${ }^{3}$ \\ Shigeo Yaguchi ${ }^{3}$ \\ Ryohei Koide ${ }^{4}$}

'Department of Ophthalmology, Saitama National Hospital, Saitama, Japan; ${ }^{2}$ Department of Clinical Pathology, Showa University

Fujigaoka Hospital, Yokohama, Japan; ${ }^{3}$ Department of Ophthalmology, Showa University Fujigaoka Rehabilitation Hospital, Yokohama, Japan; ${ }^{4}$ Department of Ophthalmology, Showa University School of Medicine, Tokyo, Japan
Correspondence: Masahiko Ayaki Department of Ophthalmology, Saitama National Hospital, 2-I Suwa, Wako, Saitama, Japan 3510I02

Tel +8 I 9022 II 8355

Fax +8I 33705 480I

Email mayaki@olive.ocn.ne.jp
Purpose: Epithelial disorders after eye surgery can result in visual deterioration and patient discomfort. Such disorders may be caused by drug toxicity. In the present study, we evaluated the toxicity of ophthalmic solutions, with or without benzalkonium chloride (BAK) as the preservative, used for postoperative care.

Methods: A range of commercially available antibiotic and anti-inflammatory ophthalmic solutions used postoperatively (ie, levofloxacin, moxifloxacin, gatifloxacin, norfloxacin, tosufloxacin, dibekacin, cefmenoxime, diclofenac, bromfenac, pranoprofen, betamethasone, and fluoromethorone) were assessed in three corneal cell lines and one conjunctival cell line. All antibiotic solutions were BAK free. Cell viability was determined with the 3-(4,5-dimethyl-2 thiazoyl)-2,5-diphenyl-2H-tetrazolium bromide (MTT) assay after cells had been exposed to the drugs for $48 \mathrm{~h}$. The effects of preservatives on cell viability were also determined. Toxicity was compared using the cell viability score (CVS).

Results: Based on results of the MTT assay and CVS, the order of cell viability after exposure to the antibiotic solutions was cefmenoxime $\geq$ tosufloxicin $\geq$ dibekacin $\geq$ levofloxacin $\geq$ norfloxacin $=$ gatifloxacin $=$ moxifloxacin . For the anti-inflammatory solutions, the order of cell viability was betamethasone $\geq$ betamethasone + fradiomycin $>$ preservative-free diclofenac $\geq$ preservative-free bromfenac $>>0.02 \%$ fluoromethorone $\geq 0.1 \%$ fluoromethorone $=$ diclofenac + preservative $=$ bromfenac + preservative $=$ pranoprofen. The anti-inflammatory drugs were more toxic than the antibiotics. The toxicity of antibiotic drugs against ocular surface cells was dependent on the pharmaceutical components of the solution, whereas that of the anti-inflammatory drugs was dependent on both the pharmaceutical components and the preservatives.

Conclusion: Postoperative drug-induced epitheliopathy may be caused primarily by anti-inflammatory drugs. CVS is useful in comparing the cytotoxicity of different drugs.

Keywords: toxicity, preservative, cornea, eye

\section{Introduction}

Common preservatives used in ophthalmic solutions include benzalkonium chloride (BAK), chlorobutanol, methyl paraoxybenzoate, propyl paraoxybenzoate, and boric acid. The toxicity of these preservatives against ocular surface cells, namely the cornea and conjunctiva, has been investigated extensively ${ }^{1-10}$ because epithelial disorders are of particular concern postoperatively, as well as in patients using eye drops over the longer term, and those with dry eye. In the present study, we examined the toxicity of ophthalmic solutions commonly used after eye surgery to control infection and inflammation in a bioassay using four established ocular surface cell lines. A further 
aim of the present study was to develop a scoring method of cell viability to enable the easy comparison of drugs, because many toxicity studies use multiple methods to evaluate cell damage and data evaluation consequently becomes complicated.

\section{Material and methods}

The commercially available cell lines used in the present study were the SIRC (rabbit corneal epithelium; ATCC CCL-60; American Type Culture Collection (ATCC), Manassas, VA, USA), BCE C/D-1b (bovine corneal epithelial cells; JCRB-9129; Health Science Research Resource Bank, Osaka, Japan), RC-1 (rabbit corneal epithelium; JCRB-0246; Health Science Research Resource Bank) and Chang conjunctiva (human conjunctival cells; ATCC CCL-20.2; ATCC) lines. All cells were cultured according to standard protocols provided by the distributors.

After cells had reached $80 \%-90 \%$ confluence and had been cultured under standard conditions for $48 \mathrm{~h}$, a $100 \mu \mathrm{L}$ aliquot of the culture containing approximately $2 \times 10^{4}$ cells was harvested from the culture wells. The different drugs and preservatives to be tested were diluted 10-, 20-, 100-, 1,000-, and, when necessary, 10,000-fold with phosphate buffered saline before being added to the cells in culture. Cell viability was determined after $48 \mathrm{~h}$ incubation in the presence of the test solutions using the 3-(4,5-dimethyl-2 thiazoyl)2,5-diphenyl-2H-tetrazolium bromide (MTT) assay (Sigma, St Louis, MO, USA), a quantitative colorimetric measure of mitochondrial activity as an index of cell viability and proliferation. Absorbance was read on a spectrophotometer (Benchmark Microplate Reader; Bio-Rad, Hercules, CA, USA). The MTT assay detects living cells only and the signal generated is directly proportional to the number of live cells. The viability of cells in test solutions was calculated as a percentage of cells incubated in growth medium without test solution. Experiments were repeated between eight and 16 times and the results are given as the mean \pm standard deviation (SD).

Because the results of preliminary experiments indicated that viability increased markedly in solutions that had been diluted 20-fold or more and the differences among the drugs were evident enough in 10 -fold diluted solutions, we expressed the results as a cell viability score (CVS50), a number of cell lines with viability $\geq 50 \%$ in the presence of a 10 -fold dilution of the drug, to enable easy comparison of the effects of different drugs. This concept is similar to the $\mathrm{MIC}_{50}$ (ie, the minimum inhibitory concentration of a drug required to inhibit the growth of $50 \%$ of organisms).

The antibiotic and anti-inflammatory drugs evaluated in the present study are listed in Table 1. The ophthalmic solution preservatives tested in the present study were $0.01 \%$ BAK (Wako Pure Chemical Industries, Osaka, Japan), 0.5\% chlorobutanol (Wako), 1.0\% polysorbate 80 (Tween 20; ICN Biomedicals, Aurora, OH, USA), $0.04 \%$ methyl paraoxybenzoate (Wako), and $0.04 \%$ propyl paraoxybenzoate (Wako). All preservatives were tested at commonly used concentrations.

\section{Results}

For all cell lines tested, cell viability after exposure to cefmenoxime was $\geq 80 \%$ (Figure 1 ). Cell viability after exposure of cells to the fluoroquinolones was concentration dependent, with $\geq 80 \%$ viability observed for solutions diluted 100-fold or more. Fluoroquinolones had less cell viability than the others except for tosufloxicin. Low toxicity was observed for betamethasone-containing drugs without BAK or polysorbate as the preservative (Figure 2). The cell viability of the other anti-inflammatory drugs was clearly concentration dependent. BAK-containing anti-inflammatory drugs had less cell viability than the drugs without BAK.

Table I Antibiotic ophthalmic solutions evaluated in the present study

\begin{tabular}{llll}
\hline Active component & Trade name & Preservative & CVS50* \\
\hline Levofloxacin (0.5\%) & Cravit (Santen, Osaka, Japan) Quixin (in US; & No & 3 \\
& Vistakon, Jacksonville, FL, USA; with 0.005\% BAK) & & I \\
Moxifloxacin (0.5\%) & Vigamox (Alcon, Fort Worth, TX, USA) & No & 2 \\
Gatifloxacin (0.3\%) & Gatiflo (Senju, Osaka, Japan) Zymar (in US; & No \\
& Allergan, Irvine, CA, USA; with 0.005\% BAK) & & No \\
Norfloxacin (0.3\%) & Noflo (Banyu, Tokyo, Japan) & No \\
Tosufloxacin (0.3\%) & Tosuflo (Nitto, Nagoya, Japan) & No \\
Dibekacin (0.5\%) & Panimycin (Meiji, Tokyo, Japan) & $0.026 \%$ methyl paraoxybenzoate, 0.014\% \\
Cefmenoxime (0.5\%) & Bestron (Kaken, Tokyo, Japan) & propyl paraoxybenzoate, boric acid \\
\hline
\end{tabular}

Notes: *Number of cell lines with viability $\geq 50 \%$ in the presence of a 10 -fold dilution of the drug. Abbreviation: BAK, benzalkonium chloride. 


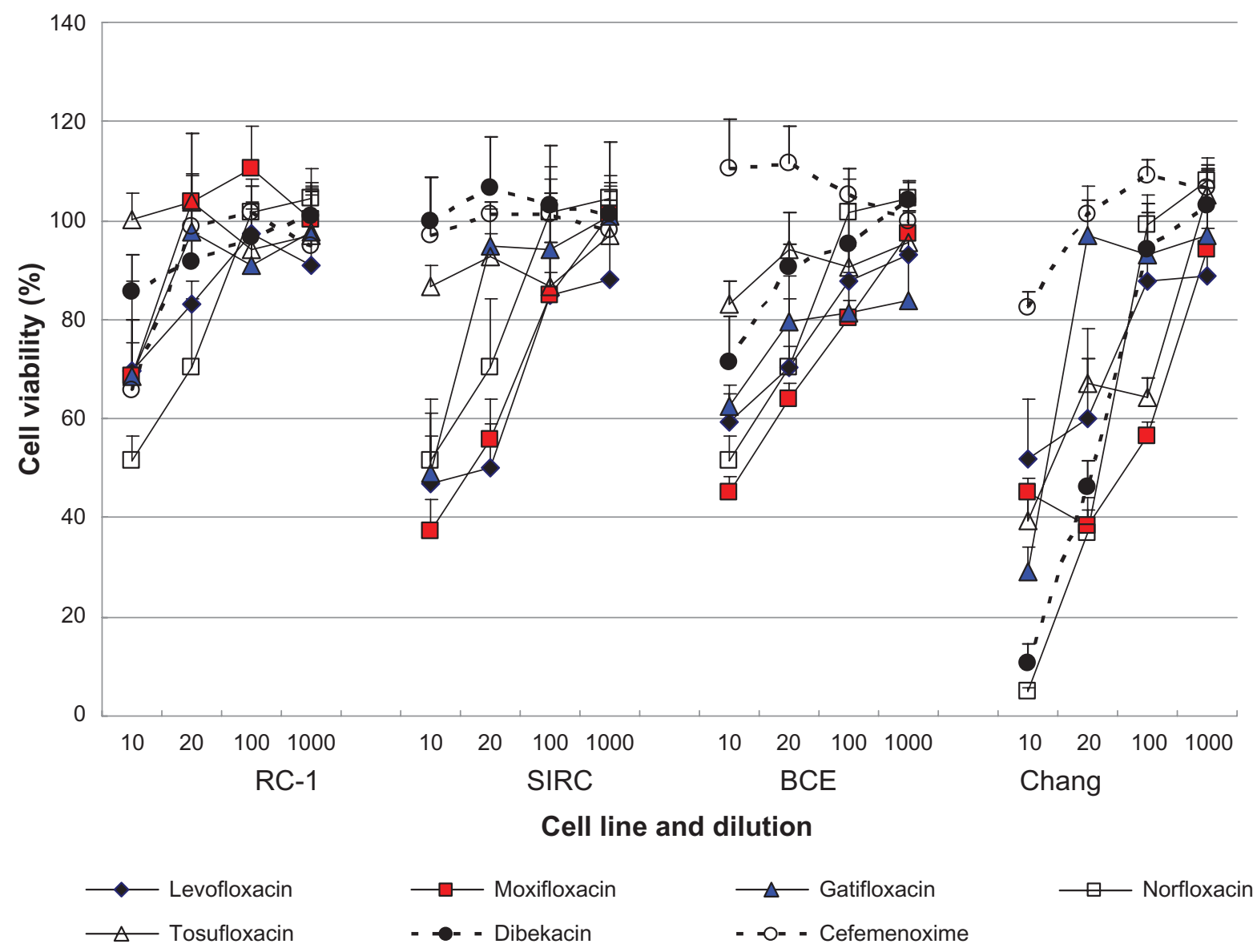

Figure I Effects of antibiotic ophthalmic solutions on the viability of cultured rabbit corneal epithelial cells (RC-I and SIRC), bovine corneal epithelial cells (BCE), and human conjunctival cells (Chang) after $48 \mathrm{~h}$ exposure. Data are the mean \pm SD. Cefmenoxime was the least toxic. The cell viability score was determined and the order of cell viability was cefmenoxime $\geq$ tosufloxicin $\geq$ dibekacin $\geq$ levofloxacin $\geq$ norfloxacin $=$ gatifloxacin $=$ moxifloxacin $($ Table I).

Nonsteroidal anti-inflammatory drugs had less cell viability than fluoromethorone with same concentration of BAK.

Using CVS50 as an indicator of cytotoxicity, the order of cell viability after exposure to the antibiotic solutions was determined to be cefmenoxime $\geq$ tosufloxicin $\geq$ dibekacin $\geq$ levofloxacin $\geq$ norfloxacin $=$ gatifloxacin $=$ mox ifloxacin (Table 1), whereas that for the anti-inflammatory drugs was betamethasone $\geq$ betamethasone + fradiomycin $>$ preservative-free diclofenac $\geq$ preservative-free bromfenac $>>0.02 \%$ fluoromethorone $\geq 0.1 \%$ fluoromethorone $=$ diclofenac + preservative $($ Diclod $)=$ bromfenac + pre servative $($ Bronuck $)=$ pranoprofen $($ Table 2$)$. The calculated CVS50 of the antibiotics ranged between one and four, whereas that of anti-inflammatory drugs preserved with BAK and Diclod was zero. These data are consistent with the results presented in Figures 1 and 2, which indicate that cell viability after exposure to antibiotics was generally higher than after exposure of cells to anti-inflammatory drugs.

Of the preservatives tested, BAK and polysorbate were cytotoxic to all cell lines (Figure 3 ). Propyl paraoxybenzoate exhibited cytotoxicity only in the SIRC and conjunctival cell lines, whereas chlorobutanol and methyl paraoxybenzoate did not exhibit any cytotoxic effects.

\section{Discussion}

The fluoroquinolones are broad-spectrum antibiotics that are the most commonly used drugs for the pre- and postoperative control of infection after eye surgery. In the present study, cefmenoxime, dibekacin, and tosufloxacin appeared to be the least cytotoxic. These results are partially consistent with those of a previous study performed in a single cell line ${ }^{11}$ and support previous reports that levofloxacin is less toxic than moxifloxacin ${ }^{12}$ or gatifloxacin. ${ }^{13}$ Many previous studies evaluating the cytotoxicity of fluoroquinolones have used solutions preserved with BAK, ${ }^{14,15}$ which had a significant effect on the results. However, in the present study we were able to evaluate the toxicity of the pharmaceutical components of the ophthalmic solutions because we used preservative-free fluoroquinolone solutions. The results of the present study indicate that antibiotics are more toxic to conjunctival cells 


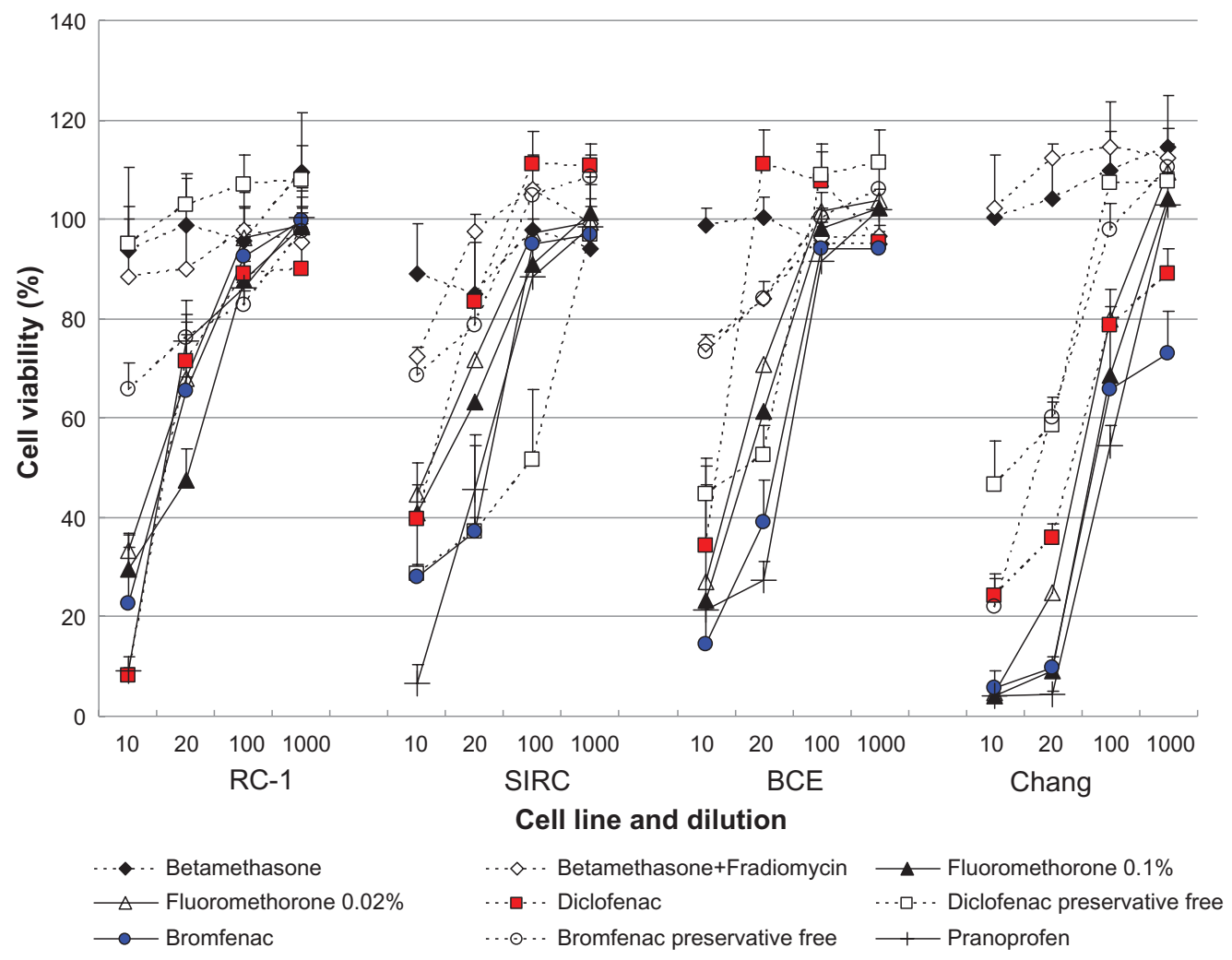

Figure 2 Effects of anti-inflammatory ophthalmic solutions on the viability of cultured rabbit corneal epithelial cells (RC-I and SIRC), bovine corneal epithelial cells (BCE), and human conjunctival cells (Chang) after $48 \mathrm{~h}$ exposure. Data are the mean \pm SD. Data for benzalkonium chloride (BAK)-free drugs are indicated by the dotted lines. Cell viability was greater in all BAK-free solutions, except for Diclod, compared with solutions containing BAK. The cell viability score was determined and the order of viability was betamethasone $\geq$ betamethasone + fradiomycin $>$ preservative-free diclofenac $\geq$ preservative-free bromfenac $>>0.02 \%$ fluoromethorone $\geq 0.1 \%$ fluoromethorone $=$ diclofenac + preservative $($ Diclod $)=$ bromfenac + preservative $($ Bronuck $)=$ pranoprofen .

than to corneal cells, except for cefmenoxime, which was not cytotoxic against any of the cell lines used.

Dose-dependent cytotoxicity was observed for all anti-inflammatory drugs preserved with BAK in all cell lines. The corneal toxicity of preservative-containing solutions of diclofenac ${ }^{16-18}$ and bromfenac ${ }^{19}$ has already been documented and the present study further revealed that preservative-free diclofenac and bromfenac exhibit considerable toxicity. Pranoprofen preserved with BAK exhibited the greatest toxicity, although this may be due to the fact that

Table 2 Anti-inflammatory ophthalmic solutions evaluated in the present study

\begin{tabular}{|c|c|c|c|}
\hline Active component & Trade name & Preservative & CVS50* \\
\hline Betamethasone $(0.1 \%)$ & Rinderon (Shinogi, Osaka, Japan) & $\begin{array}{l}0.05 \% \text { methyl paraoxybenzoate, } 0.02 \% \\
\text { propyl paraoxybenzoate }\end{array}$ & 4 \\
\hline $\begin{array}{l}\text { Betamethasone }(0.1 \%)+ \\
\text { fradiomycin }(0.35 \%)\end{array}$ & Rinderon A (Shionogi) & Same as Rinderon & 4 \\
\hline Fluoromethorone (0.1\%) & Flumethoron 0.1\% (Santen, Osaka, Japan) & $0.005 \%$ BAK, polysorbate 80 & 0 \\
\hline Fluoromethorone $(0.02 \%)$ & Flumethoron 0.02\% (Santen) & 0.005\% BAK, polysorbate 80 & 0 \\
\hline Diclofenac (0.1\%) & $\begin{array}{l}\text { Diclod (Wakamoto, Tokyo, Japan) Voltaren } \\
\text { Ophthalmic Solution (in US; Novartis, East } \\
\text { Hanover, NJ, USA) }\end{array}$ & Chlorobutanol, polysorbate 80 , boric acid & 0 \\
\hline Preservative-free diclofenac & No brand name (experimental use only) & No & I \\
\hline Bromfenac $(0.1 \%)$ & $\begin{array}{l}\text { Bronuck (Senju, Osaka, Japan) Xibrom (in } \\
\text { US; ISTA Pharmaceuticals, Irvine, CA, USA) }\end{array}$ & 0.005\% BAK, polysorbate 80 & 0 \\
\hline Preservative-free bromfenac & No brand name (experimental use only) & No & 3 \\
\hline Pranoprofen (0.1\%) & Niflan (Senju) & $0.007 \%$ BAK, polysorbate 80 , boric acid & 0 \\
\hline
\end{tabular}

Notes: *Number of cell lines with viability $\geq 50 \%$ in the presence of a 10 -fold dilution of the drug. Abbreviation: BAK, benzalkonium chloride. 


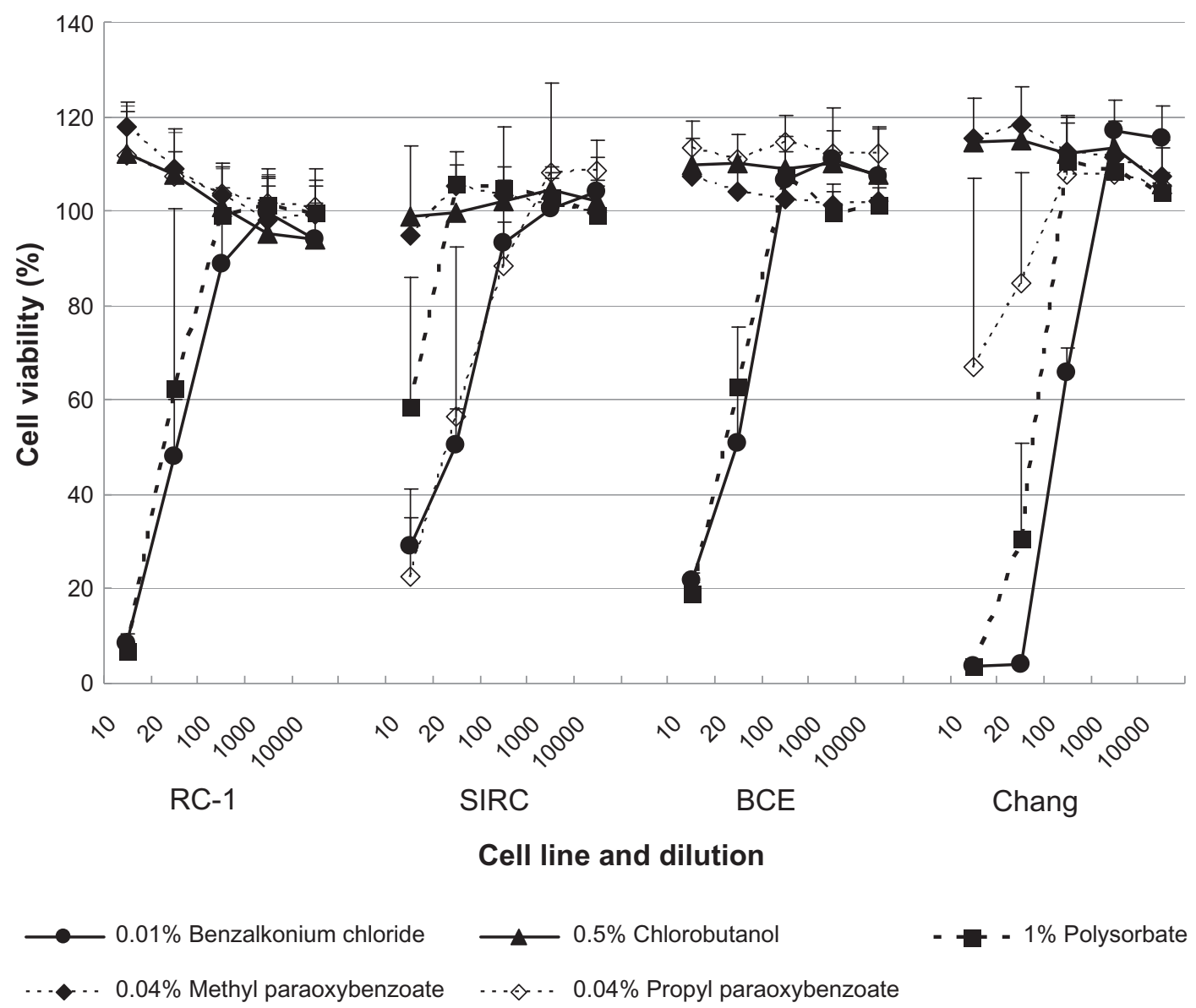

Figure 3 Effects of preservatives on the viability of cultured rabbit corneal epithelial cells (RC-I and SIRC), bovine corneal epithelial cells (BCE), and human conjunctival cells (Chang) after $48 \mathrm{~h}$ exposure. Data are the mean \pm SD. Benzalkonium chloride and polysorbate were shown to have dose-dependent cytotoxic effects.

this solution contained the highest concentration of BAK. Of the actual preservatives evaluated in the present study, the cytotoxic effects of BAK, polysorbate, ${ }^{8}$ and cholorobutanol ${ }^{9}$ were comparable to those reported previously; both methyl paraoxybenzoate and chlorobutanol exhibited significant cytotoxic effects at high concentrations. ${ }^{10}$

On the basis of the results of the present study, it is likely that any postoperative epithelial damage may be caused primarily by anti-inflammatory drugs because the cell viability determined in the present study for the routinely used nonsteroidal anti-inflammatory drugs (ie, Diclod and Bronuck) were very low compared with values determined for the antibiotics. CVS50 was demonstrated to be a useful system for comparisons of the cytotoxicity of different ophthalmic solutions, as evidenced by comparable results for MTT assay using multiple cell lines and various drug concentrations. In addition, we calculated another number [(number of cell lines with viability $>80 \%$ ) - (number of cell lines with viability $<40 \%$ )] for each drug at a 10 -fold dilution based on the cell viability of different cell lines and the order of this number for tested solution was the same as that for CVS50. Considering biological fluctuations in cellular reaction to the drugs, we have to be careful of evaluation of the value of cell viability and the method for expressing general trend such as CVS50 may be one of the solutions.

The limitations of the present study include the use of bioassays only to evaluate cytotoxicity and the relatively long exposure time. However, the standardization of methods to evaluate the toxicity of ophthalmic solutions is still under development and the cytotoxic and/or ocular toxic effects of drugs clearly need to be evaluated more comprehensively. In the present study, we attempted to address these issues by evaluating the effects of a range of drug concentrations in four commercially available cell lines. We were able to compare the cytotoxic effects of the drugs easily using the CVS as well as graphically by plotting cell viability against drug concentration. With regard to exposure time, optimal exposure times for in vitro cell culture systems have not yet been established. It is common to use $48 \mathrm{~h}$ exposure followed by $48 \mathrm{~h}$ recovery in in vitro cytotoxicity assays; however, 
epithelial cells proliferate rapidly and further studies in epithelial cells are needed using shorter exposure times.

\section{Conclusion}

In conclusion, the toxicity of a wide range of BAK-free ophthalmic solutions used postoperatively to control infection and inflammation was evaluated in four ocular surface cell lines. Because sufficient data regarding cell viability from multiple cell lines with different drug concentrations were available, the results of the MTT assay were expressed as CVS to enable the simple comparison of drug effects. The cytotoxicity of antibiotics was found to be dependent on the pharmaceutical components of the solution, whereas the toxicity of anti-inflammatory drugs was found to be dependent on both the pharmaceutical components of the solution and the preservative used. Based on the results of the present study, postoperative drug-induced epitheliopathy is most likely due to the effects of anti-inflammatory drugs.

\section{Disclosure}

The authors report no conflicts of interest in this work.

\section{References}

1. Pfister RR, Burstein NL. The effects of ophthalmic drugs, vehicles, and preservatives on corneal epithelium: a scanning electron microscope study. Invest Ophthalmol. 1976;15(4):246-259.

2. Burstein NL, Klyce SD. Electrophysiologic and morphologic effects of ophthalmic preparations on rabbit cornea epithelium. Invest Ophthalmol Vis Sci. 1977;16(10):899-911.

3. Burstein NL. Corneal cytotoxicity of topically applied drugs, vehicles, and preservatives. Surv Ophthalmol. 1980;25(1):15-30.

4. Burstein NL. Preservative cytotoxic threshold for benzalkonium chloride and chlorhexidine digluconate in cat and rabbit corneas. Invest Ophthalmol Vis Sci. 1980;19(3):308-313.

5. Burnstein NL. The effect of topical drugs and preservatives in the tears and corneal epithelium in dry eye. Trans Ophthalmol Soc U K. 1985; 104(Pt 4):402-409.
6. Baudouin C. Allergic reaction to topical eyedrops. Curr Opin Allergy Clin Immunol. 2005;5(5):459-463.

7. Hubbard SA. Comparative toxicology of borates. Biol Trace Elem Res. 1998;66(1-3):343-357.

8. Quiroga R, Klintworth GK. The pathogenesis of corneal edema induced by Tween 80. Am J Pathol. 1967;51(6):977-999.

9. Tripathi BJ, Tripathi RC. Cytotoxic effects of benzalkonium chloride and chlorobutanol on human corneal epithelial cells in vitro. Lens Eye Toxic Res. 1989;6(3):395-403.

10. Epstein SP, Ahdoot M, Marcus E, Asbell PA. Comparative toxicity of preservatives on immortalized corneal and conjunctival epithelial cells. J Ocul Pharmacol Ther. 2009;25(2):113-119.

11. Sakurai M, Hatou S, Mochizuki H. [In vitro effects of fluoroquinolones on corneal epithelial cells and keratocytes]. Atarashii Ganka. 2006;23:1209-1212. Japanese.

12. Kim SY, Lim JA, Choi JS, Choi EC, Joo CK. Comparison of antibiotic effect and corneal epithelial toxicity of levofloxacin and moxifloxacin in vitro. Cornea. 2007;26(6):720-725.

13. Sosa AB, Epstein SP, Asbell PA. Evaluation of toxicity of commercial ophthalmic fluoroquinolone antibiotics as assessed on immortalized corneal and conjunctival epithelial cells. Cornea. 2008;27(8): 930-934.

14. Walter K, Tyler ME. Severe corneal toxicity after topical fluoroquinolone therapy: report of two cases. Cornea. 2006;25(7):855-857.

15. Dutot M, Pouzaud F, Larosche I, Brignole-Baudouin F, Warnet JM, Rat P. Fluoroquinolone eye drop-induced cytotoxicity: role of preservative in $\mathrm{P} 2 \mathrm{X} 7$ cell death receptor activation and apoptosis. Invest Ophthalmol Vis Sci. 2006;47(7):2812-2819.

16. Guidera AC, Luchs JI, Udell IJ. Keratitis, ulceration, and perforation associated with topical nonsteroidal anti-inflammatory drugs. Ophthalmology. 2001;108(5):936-944.

17. O'Brien TP, Li QJ, Sauerburger F, Reviglio VE, Rana T, Ashraf MF. The role of matrix metalloproteinases in ulcerative keratolysis associated with perioperative diclofenac use. Ophthalmology. 2001;108(4): 656-659.

18. Hsu JK, Johnston WT, Read RW, et al. Histopathology of corneal melting associated with diclofenac use after refractive surgery. $J$ Cataract Refract Surg. 2003;29(2):250-256.

19. Isawi H, Dhaliwal DK. Corneal melting and perforation in Stevens Johnson syndrome following topical bromfenac use. $J$ Cataract Refract Surg. 2007;33(9):1644-1646.
Clinical Ophthalmology

\section{Publish your work in this journal}

Clinical Ophthalmology is an international, peer-reviewed journal covering all subspecialties within ophthalmology. Key topics include: Optometry; Visual science; Pharmacology and drug therapy in eye diseases; Basic Sciences; Primary and Secondary eye care; Patient Safety and Quality of Care Improvements. This journal is indexed on Submit your manuscript here: http://www.dovepress.com/clinical-ophthalmology-journal

\section{Dovepress}

PubMed Central and CAS, and is the official journal of The Society of Clinical Ophthalmology (SCO). The manuscript management system is completely online and includes a very quick and fair peer-review system, which is all easy to use. Visit http://www.dovepress.com/ testimonials.php to read real quotes from published authors. 